\title{
IMPLEMENTATION OF MCKINSEY 7S MANAGEMENT STRATEGY CONCEPTS FOR STARTUP BUSINESS: FRUIT COMBINING
}

\author{
Mamun Mukhamad*, Syah Tantri Yanuar Rahmat, Pusaka Semerdanta, \\ Darmansyah H.S. \\ Faculty of Economics and Business, University of Esa Unggul, Jakarta, Indonesia \\ *E-mail: maxmounth@gmail.com
}

\begin{abstract}
Strategies are critical elements in organizational functioning. Although most organizations have good strategies, a successful strategy implementation still becomes a major challenge. Despite the clear importance of this management area and the apparent problems associated with its execution, it has however, been substantially neglected by industries. The objective of the study is to determine the barriers of strategy execution in food combining startup business, by focusing on vision barrier, leadership barrier, process barrier and people's behaviour barrier. The study constitutes the review of theoretical and empirical literature relevant to the subject. The key barriers to strategy execution were identified and discussed; which include vision barrier, leadership barrier, process and resources barrier, as well as people's behaviour barrier. The research was compiled from theoretical, conceptual and empirical review of literature; and a summary as well as conclusion were drawn. Translation of vision to clear objective and aligning it to strategy is still a big challenge. In addition to leader's role of communicating strategy to the employee; leadership style, approach and perceptions are also critical to implementation. Unable to adopt the best approach with a given type of strategy and using the best communication tactic implementation would likely lead to failure. Aligning process resources, structures and program in the implementation of strategy is also critical to implementation failure, to which a problem is likely occurred. Moreover, individual's behaviours determine if the strategy will be implemented or not. Individuals must be assigned to duties that motivate them; otherwise, they will not be committed to the organization operations. The author recommends that specific studies be conducted on the effective tools to measure and control performance, so that it could help overcoming barriers of strategy execution.
\end{abstract}

\section{KEY WORDS}

Barriers of strategy execution, strategy implementation, leadership, vision, process, individual behaviour.

How do you analyze how well your organization is positioned to achieve its intended objective? This is a question that has been asked for many years and there are many different answers. Some approaches look at the internal factors while others look at the external ones; some combine these perspectives while others look for congruence between various aspects of the organization being studied. Ultimately, the issue comes down to which factors to study. While some models of organizational effectiveness go in and out of fashion, one that has persisted is the McKinsey $7-S$ framework. Developed in the early 1980 s by Tom Peters and Robert Waterman, two consultants working at the McKinsey \& Company consulting firm, the basic premise of the model is that there are seven internal aspects of an organization that need to be aligned if it is to be successful. The 7-S model can be used in a wide variety of situations, where an alignment perspective is useful. For example, to help improving the performance of a company, examine the likely effects of future changes within a company, align departments and processes during a merger or acquisition, determine what the best way to implement a proposed strategy is.

The McKinsey 7-S model can be applied to elements of a team or a project as well. The alignment issues would still apply, regardless of how you decide to define the scope of the areas you study. 


\section{METHODS OF RESEARCH}

The McKinsey 7-S model involves seven interdependent factors which are categorized as either "hard" or "soft" elements:

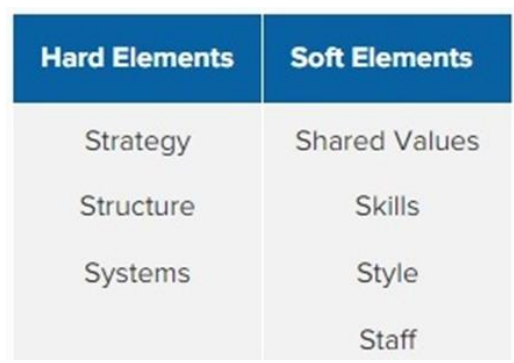

Figure 1 - Seven Interdependent Factors

"Hard" elements are easier to define or identify, and management can directly influence them: These are strategy statements; organization charts and reporting lines; and formal processes as well as IT systems.

"Soft" elements, on the other hand, can be more difficult to describe, and are less tangible and more influenced by culture. However, these soft elements are as important as the hard elements if the organization wants to be successful.

The way the model is presented in the Figure below depicts the interdependency of the elements and indicates how a change in one could affect the others.

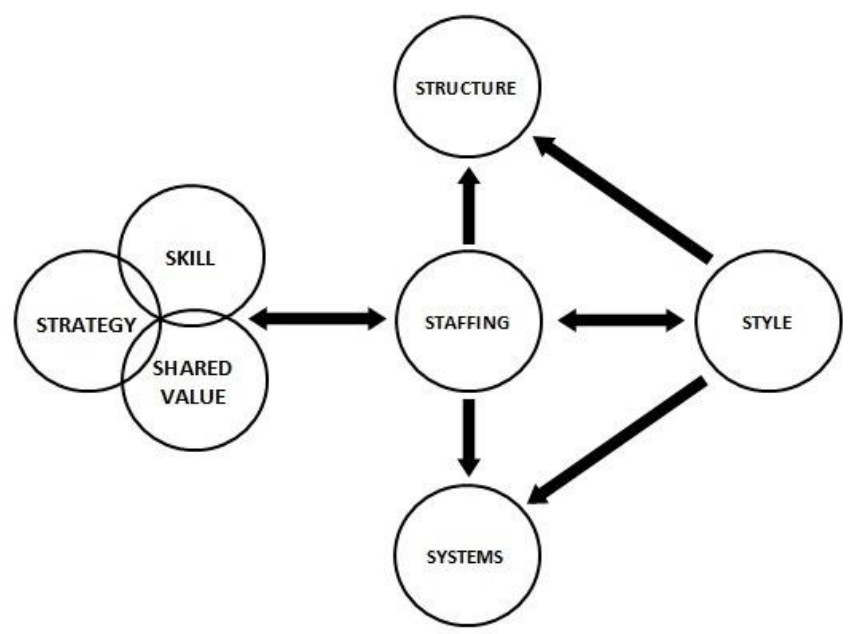

Figure 2 - Concept of Human Resource Management (Source: Harvard Business School Management Consulting Club)

Let's take a look at each of the elements specifically:

- Strategy: the plan devised to maintain and build competitive advantage over the competition;

- Structure: the way the organization is structured and who reports to whom;

- Systems: the daily activities and procedures that staff members engage in to get the job done;

- Shared Values: called "super ordinate goals"; when the model was first developed, these are the core values of the company that are evidenced in the corporate culture and general work ethic;

- Style: the style of leadership adopted;

- Staff: the employees and their common capabilities;

- Skills: the actual skills and competencies of the employees working for the company. 


\section{RESULTS AND DISCUSSION}

PT Redceri Indonesia is a new company engaged in Fruit Combining. The company is located in Warehousing Area Bizlink Block X11/20 Citra Raya, Pemda Tigaraksa St. The location is included in the administrative area of Sukamulya, Cikupa Sub-district, Tangerang Regency, Banten Province. The company offers Fruit Combining products in the form of a combination of jelly with fresh fruits in the packaging.

The selection of PT Redceri Indonesia products is based on the high level of public awareness to consume the fruit, but in its implementation, it collides with various obstacles. Today, people are well aware that consuming fruits regularly in sufficient quantities can meet the intake of nutritional needs for the body; such as vitamins, phytochemicals, fiber and minerals, as well as helping to reduce the risk of many diseases. However, the constraint of the majority of people to self-consume fruit is a matter of practicality, especially if the fruit consumed has a thick skin that needs to be peeled first. Another obstacle is that; it is not easy to keep the freshness of fruit, and consumer's behaviour shift from conventional to instant way. Many people feel bothered to eat fruit, but this cannot be an excuse. To bridge this constraint, PT Redceri Indonesia offers a practical product (ready to eat), without ruling out the essence of the benefits of consuming fresh fruit.

The vision of PT Redceri Indonesia is "To be the best company in the food and beverage industry by creating natural products".

While the company's missions are as follows: providing natural products by utilizing hygienic preservation technology, maintain and increase employee's potential by developing science, and maintain the integrity of the company's chain.

While the goal of the company is to become a leading food and nutrition company and be trusted by all stakeholders, also to become a reference for joint benefit creation initiatives. With Fruit Combining products offered, the company aims to gain $5 \%$ market share of fruit demand in the first year of production.

Redceri Pure Fruit Jelly's product tagline is 'Your Pure Fruit Jellycious', while its positioning statement is 'For a healthy Indonesian people". Redceri Pure Fruit Jelly is a Fruit Combining that combines jelly with fresh fruits as a halal product, also as practical and tasteful vitamin intake which is different, since only Redceri Pure Fruit Jelly as domestic products that is processed both in hygienic and modern technology.

PT Redceri Indonesia's strategy is to strengthen Research \& Development in order to conduct market research and product development. This is to support the market penetration strategy in the medium term from all-round marketing to multi-segment marketing, based on market segmentation that has been done by the company. To that end, in the management of human resources, the company designed to emphasize systematic plans and comprehensive actions to ensure the success of the company's operations. In the selection of generic strategies, the company considers that the new company will now enter the Fruit Combining industry. According to Porter (1985), as a new company is about to enter an industry and tries to catch up with other competitors who have been in the industry, there are only two choices of generic strategies; namely focus on low cost or differentiation.

In Fruit Combining industry, the focus of consumers is to find the product with the cheapest price, good taste, healthy and easy to get. So, in line with the results of Porter Five Forces analysis that has been done by the previous company, a suitable strategy that needs to be applied by the company as a newcomer is low-cost focus. As the first local company to produce Fruit Combining, it allows the company to offer a lower total cost compared to that offered by competitors from overseas. This is done by the company by utilizing the difference between distribution cost and import duty.

Strategies can be identified on the basis of most elements of the organization's orientation to market product development. Miles and Snow (1978) stated that there are four types of strategies; namely Prospectors, Defenders, Analyzers, and Reactors. 'The focus is primarily on strategy and its correlation, not the process used to formulate and implement the strategy' (Snow and Hambrick, 1980). 
As for the overall objectives of the company, it is divided into three strategies that will be executed as follows:

- Short-Term: Offering Fruit Combining products for DKI Jakarta and Banten communities of 16-30 years old, with a focus on low-cost and all-round marketing strategies. At this stage, the company places itself as a stage Analyzers, which follows the products that have entered the market first;

- Medium-Term: Develop Fruit Combining product with the development of variant and taste based on age group of Jakarta and Banten. At this stage, the company positioned itself as a Prospector by leveraging the power of $R N D$ by creating products of different types and styles;

- Long-Term:Expanding the market for Fruit Combining products in Indonesian territory outside DKI Jakarta and Banten.

The company's strategy for the medium term is to do various marketing multifarious. Currently, competitors are entering the market with the same marketing, offering their products in general without segmenting the needs of Indonesian consumers. The ease of the company to segment the Indonesian market supports the company to enter the market with miscellaneous marketing, which classifies the market based on the level of consumer needs resulting from market research conducted by developing several types of products offered.

A company culture is similar to a person's personality. Company culture is shared norms that act as the basis for an individual in the organization. Because company culture has a strong influence on the behaviour of all employees, the company culture also has a major impact on the company's ability to change its strategic direction. If within the company there is a change in mission, objectives, strategy or policy; if steps are taken in accordance with the company culture, then the process of strategy implementation will be easier to do.

Culture, as defined above, can be regarded as a set of values or beliefs that produce certain patterns of behaviour collectively in the corporation. With these shared values, the common problems that arise as a result of environmental changes can be effectively overcomed, because there is a togetherness built on mutual trust with each other. Based on culture definition, the company has a work culture motto: "Quality first, working hard and family number one". Family is defined as internal and external parties that are interconnected in the company's business processes. Internal party refers to all employees of the company along with their respective families, while the external party refers to the work partner that is the supplier, distributor and customer.

Development is a process created to improve conceptual ability, decision-making ability, and expand relationships. Training is a process created to increase knowledge and technical skills, or improve employee's performance. The purposes of development and training are:

- Introduction to business background, rules and work patterns;

- Embed the culture, vision and mission of the company;

- Ensure employees can reach the standards set by the company and increasing employee's productivity;

- Maintain the quality of products and services, and increasing company sales.

Assessing training needs, the main objective of determining the need for this training is to gather as much relevant information as possible to find out and / or determine whether or not the training within the company is necessary. In this stage, there are three kinds of training needs. The assessment of training is needed for all employees in a job classification, regardless of data on the performance of a particular employee. Over performance discrepancies, assessment of training needs is based on observations on issues, interviews, questionnaires, and performance evaluations/assessments performed by each employee.

Training Methods, the technique used by the company which is on the job training, i.e. employees are trained on new jobs by an experienced trainer, usually other more senior employees.

General Principles For Training Methods, the chosen training method should meet the following principles: motivate the trainees, showing the skills, consistent with training content, 
participants participate actively, provides opportunities for skills expansion, provide feedback, encourage from training to work, and cost effective.

Evaluating training program effectiveness, the purpose of this stage is to test whether the training is effective in achieving its established goals.

\begin{tabular}{|l|c|c|c|c|c|c|c|c|c|c|c|c|}
\hline \multirow{2}{*}{ Pelatihan } & \multicolumn{7}{|c|}{ Bulan Ke- } & \multicolumn{1}{c|}{} \\
\hline & 1 & 2 & 3 & 4 & 5 & 6 & 7 & 8 & 9 & 10 & 11 & 12 \\
\hline New Employee \& On The Job Training & & & & & & & & & & & & \\
\hline Interpersonal \& Communication Skill & & & & & & & & & & & & \\
\hline Managerial Skill & & & & & & & & & & & & \\
\hline Supervisory Course & & & & & & & & & & & & \\
\hline Quality Control Technique \& Method & & & & & & & & & & & & \\
\hline Productivity & & & & & & & & & & & & \\
\hline Safety Issue & & & & & & & & & & & & \\
\hline Public Speaking & & & & & & & & & & & & \\
\hline Negotiation Skill & & & & & & & & & & & & \\
\hline Business low & & & & & & & & & & & & \\
\hline Accounting \& Tax & & & & & & & & & & & &
\end{tabular}

Figure 3 - Training Plan

The purposes of organizational structure planning and human resources for PT Redceri Indonesia are to provide a compassionate employee, be the best workplace for employees, and being a place of training and employee development that will support the company's strategic goals. The goals of organizational structure and human resource planning for PT Redceri Indonesia are to keep the turnover rate less than $1 \%$ per year and allocate funds for employee development and training, which ranged from Rp. 100,000,000.- up to Rp. $200,000,000 .-$. The company adopts Traditional organizational structure. This structure is based on the functions of divisions and departments. This is the type of structure that follows the rules and procedures of the organization, and is characterized by a clear line of authority across all levels of management. The type of structure used is the functional structure - this type of organizational structure put people in groups according to the function they perform in the professional life, or according to the function performed in the organization. The organization is led by a Director and 4 Managers who are divided according to their respective departments. The organizational structure of the company is shown by the following figure:

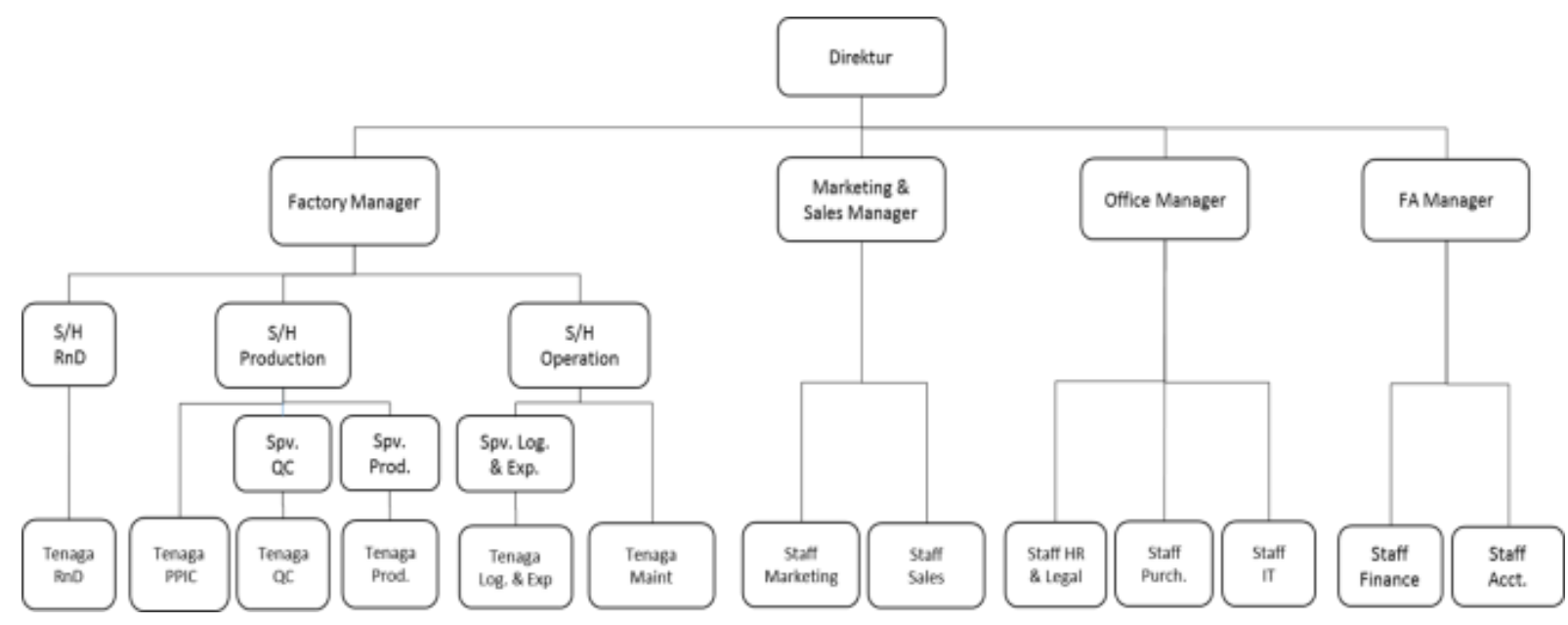

Figure 4-Organizational structure of the company 
Personnel regulations are the rules that are used by the company to control all employees to work according to the plan set by the company. Furthermore, if in the middle of the journey it turns out that there are irregularities or errors, a corrective action or improvement and refinement of the plan must be done. Employee attendance, discipline, behaviour, cooperation, job execution and maintain the work environment situation are the things that should be controlled by the company. The regulations include: working day and overtime regulations; Rest and leave regulations, employment relations and termination of employment.

In the Working Day Regulations, Working Hours and Company Overtime Calculations refer to UU No. 13 of 2003 on Manpower; Kepmenakertrans No. 102/MEN/ VI/2004 on Overtime and Overtime wages. As for the regulation of leave and rest days, the company refers to Article 79 paragraph 1-5, UU No. 13, tahun 2013 on Manpower. As for the regulations of Employment Relations and Termination of Employment (PHK), companies refer to Article 156 and Article 160 to Article 169 of UU No. 13 of 2003 on Manpower.

One of the important parts that became the object of attention of company regulations is occupational health and safety (OHS). Occupational Health and Safety is set forth in the Employment Agreement, whereby the company and each worker are fully aware that $O H S$ is a shared obligation and responsibility. In the event of a violation, the company will apply sanctions. The focuses of the company in implementing $K 3$ are preventing work accident and occupational diseases. The company's policy regulation pertaining to Occupational Health and Safety (OHS) is adjusted according to the rules of UU No. 13 Year 2003 on Manpower, UU No. 1 of 1970 on Occupational Safety, and UU no. 23 of 1992 on Health. The objectives of occupational health and safety are as follows:

- In order for each employee to be guaranteed a safety and healthy work physically, socially, and psychologically;

- In order for operational activities to run smoothly;

- In order for every equipment and work equipment to be used as well as possible;

- For all production to be kept secure;

- In order for a guarantee for the maintenance and improvement of employees' nutrition health;

- In order to increase enthusiasm, work harmonious and participation;

- In order to avoid health problems caused by the environment or working conditions;

- In order for every employee to feel safe and protected in work.

While the rights and obligations relating to Occupational Health and Safety are: provide correct information when requested by a supervisor or occupational safety officer, use the required personal protective equipment, comply with and comply with all required safety and health requirement, and ask the board to carry out all required safety and health requirements.

In OHS implementation, the company employs a special staff of the OHS section which has the following responsibilities:

- Examining the body's health, mental condition and physical capability of the workforce to be received or to be transferred in accordance with the nature of the work given;

- Checking the health of all workers under his leadership, periodically;

- Show and explain to each new worker about: conditions and dangers and what may arise in the workplace; all safeguards and protective equipment which are required in all workplaces; self-protection tools for the workforce concerned; ways and attitudes which are safe in carrying out his work;

- Responsible in the prevention of accidents and fire eradication as well as improvement of occupational safety and health; also in the provision of first aid in an accident;

- Report any accidents occurring within the workplace which they lead;

- Writing all the required safety requirements, basic OHS rules and all regulations applicable to the workplace they lead, and put all of it in places that are easily seen 
and legible and according to the instructions of the supervisor or occupational health officer.

Another important part of this company's regulation is OHS Education and Training. The implementation of OHS training can prevent unsafe behaviour and reduce unsafe environmental conditions. OHS education is also useful to give knowledge and ability to the workforce, in order to prevent accidents, develop the concepts and habits of the importance of occupational safety and health, understand the hazards present in the workplace and use occupational injury prevention measures.

In addition, the company's system also aims to build a family culture. It is carried by the company and fostered by doing various activities involving all members of the company, such as breaking the fast together, annual Gathering, and blood donor action

Leadership is the process of directing and influencing members in terms of various activities that must be done. The leadership process focuses on what leaders do; the process by which leaders use their influence to clarify organizational goals for employees, subordinates, or leads, motivate them to achieve those goals, and help create a productive culture within the organization.

PT Redceri implements Transformational leadership, in which they believe that leadership is not the ability to motivate people to work hard for their salaries, but it is the ability to change followers to become more independently directed in everything they do. The result is a mutual relationship of stimulation and elevation that converts followers into leaders, and can convert leaders into moral agents (Burns 1978, p.4).

As for the employees, PT Redceri Indonesia will build employees with the perspective of Followership Partners; in which employees are actively involved in every process of the company, have a high level of performance, and promote positive relationships within the group, Gardner (1990).

Characteristics of leaders that are being put forward by PT Redceri Indonesia are; having a high intelligence and broad general education, exemplary in speech - attitude and deeds, authoritative and have a persona, physically and mentally healthy, have good analytic ability, have good communication skills, have the skills to educate, objective, as well as honest.

The function of procurement of human resources within the company aims to obtain the workforce in the number and qualifications which are adequate and according to company needs.

Procurement of human resources begins with the conduct of manpower that needs planning, withdrawal and selection of labor, and end with employee placement.

The determination of the number of workers can be done by considering the workload within the company, as well as by calculating the amount of labour that can be available in the company at a certain period. In the manpower planning, department or human resources department in a company needs to implement the process of ANALYSIS POST or JOB ANALYSIS, which is a systematic analysis of various jobs or positions within a company.

The required labour recruitment can be obtained from various sources.

- Internal Recruitment. This can be done through promotion or transfer of employees;

- External Recruitment. Namely by recruiting new workers to fill vacancies in the company. Sources from external recruitment are such as:

Job posting in the media; Employment Bureau; Recommendations from internal workforce;

- $\quad$ Educational institutions (job-fair at university);

- Selection of labour. The purpose of the selection of labour is to seek or select the workforce in accordance with the requirements or qualifications of a particular position;

- Employee placement, after the selection process is done, it is expected that the company can make the process of placement of employees in the position or appropriate positions;

- $\quad$ Performance appraisal is intended to measure work performance that refers to the work achieved by a person in performing the tasks charged; 
- $\quad$ Training and development is aimed at eliminating the gap between elements and qualifications possessed by an employee with the elements and qualifications desired by the company;

Career development. Employees can go through several ways; namely promotion, demotion, transfer, termination of employment.

Application Point determines the employee class in accordance with the evaluation of each employee's work, where then the company divides the employees into 4 groups:

- Group A. Group A is a grouping of directors' level employees; that at this level have responsibility in terms of strategic planning and decision making, which affects company policies, procedures and practices.

- Group B. Group B is a grouping of manager level employees, which at this level has the responsibility to supervise and direct its subordinates, and to report directly to the director according to his division.

- Group C. Group C is the grouping of head section level, where at this level in the execution of work requires good interaction ability with internal and external.

- Group D. Group D is the grouping of employee level supervisors and staff, where at this level in the execution of work is more concerned with the ability of administration and physical work.

- Group E. Group E is the grouping of employees' level of personnel, where at this level in the execution of work is more concerned with physical work or the work agent.

The purpose of providing compensation is as a bond of cooperation, job satisfaction, effectiveness, motivation, employee stability, and work discipline.

Compensation is divided into two main components:

- Financial compensation, which is subdivided into direct compensation and indirect compensation;

- Non-Financial compensation.

In principle, the company's remuneration system or payroll determination is competency-based. It is a situation where a company considers the rewards to be equally given to the inputs and outputs of employees. Input in this case is how someone does something (work) to be able to achieve performance goals. It relates to what competencies the person needs to master. Whereas output is what the person achieved in his/her work.

Competency-based remuneration system equally considers 3 factors in determining the rewards given as total income received by each employee, which are:

- First Factor (Position). This is the value of the contribution given by the function of position for the organization, which can generally be seen from 3 (three) things; namely the demands of ability, problem solving and responsibility. It is this factor that determines the amount of basic salary a person receives in return for the position that he/she occupies;

- Second Factor (Individual Competence). This is the competence that is owned and brought by the person to do his/her job as required. This factor is usually taken into account in return for additional income received in the form of allowances or incentives;

- Third Factor (Performance). This is the achievement or work that is shown either individually, team or organizationally, that successfully achieve the performance target set by the organization. This factor is usually calculated in return in the form of incentives or bonuses.

The company maintains a safe and healthy working environment to support employee work convenience. The company also concerns the needs of employees in terms of career security, labour welfare and learning / training opportunities, so as to be able to face challenges and be responsible in their work.

Performance appraisal is to assess the ratio of real work to the quality standards and quantities produced by each employee. Follow-up assessments allow employees to be promoted, demoted, developed, and earned a raise. 


\section{CONCLUSION}

The result from the application of Mc.Kinsey 7S model in PT Redceri includes:

- Productivity, quality, organization, service and innovation are shared values;

- The form of organizational culture is reflected in the company's values;

- Organizational culture is the foundation for companies to create efficiency, customer satisfaction, revenue growth and competence.

\section{REFERENCES}

1. Graham Friend and Stefan Zehle, Guide To Business Planning, The Economist Newspaper

2. Katz D. \& Khan R.L. The Social Psychology of Organizations, A. Wiley International Edition, 1996.

3. R., Veithzal, Kepemimpinan dan Perilaku Organisasi, Jakarta Raya: Grafindo Perkasa, 2003.

4. Mulyadi, Sistem Perencanaan dan Pengendalian Manajemen, Edisi Ketiga, Salemba Empat, Jakarta, 2007.

5. Porter, Micheal E. (1980). Competitive Strategy. New York: Free Press.

6. Porter, Micheal E. (1985). Competitive Advantage. New York: Free Press.

7. Osterwalder, Alexander \& Pigneur, Yves. (2010). Business Model Generation. New Jersey: John Wiley \& Sons Inc.

8. Kasali. 2005. Change. Gramedia PustakaUtama. Jakarta.

9. Electronic Source: http://www.jakartaconsulting.com/publications/articles/organizationdevelopment-behavior/makna-networking

10. Tanjung, Farid Aulia, 2014, "Menyusun Business Plan: Langkah Penyusunan Business Plan": http://www.bglconline.com 